\title{
IIIIII

\section{DESENVOLVIMENTO NO ESCURO: CARTOGRAFIAS SUBJETIVAS \\ COMO LEGITIMAÇÃO DE PARTICIPAÇÃO POPULAR EM \\ CONSTRUÇÃO DE BARRAGEM}

\section{DEVELOPMENT IN THE DARK: SUBJECTIVE CARTOGRAPHS AS \\ LEGITIMATION OF POPULAR PARTICIPATION IN DAM \\ CONSTRUCTION}

\section{Mônica Thaís Souza Ribeiro ${ }^{1}$ \\ Frederico Augusto Barbosa da Silva ${ }^{2}$}

RESUMO: A percepção subjetiva dos fatos históricos e sociais é alcançada a partir da realidade local em comunidades tradicionais no interior do Brasil. A cidade de Morada Nova de Minas é apresentada neste trabalho sob a narrativa dos moradores com o objetivo de anunciar o que foi vivido a partir da ocupação das terras municipais pelas águas represadas na construção da barragem de Três Marias. O campo explorado é ressignificado quando uma população independente e altamente produtiva, retrocede ao uso de lamparinas. A metodologia do uso de entrevistas semiestruturadas parte da reflexão dos saberes orais das experiências vividas e da importância de interpretar os fatos sob a oratória de um povo não vocalizado e alienado. Grandes obras possuem argumentos complexos como neste caso, finalidades múltiplas de contenção das

${ }^{1}$ Mestra em Direito, Políticas Públicas, Estado e Desenvolvimento pelo UniCEUB. PósGraduada em Direito Público e bacharela em Direito, patrocinada pela FAPEMIG - Fundação de Amparo à Pesquisa do Estado de Minas Gerais. Currículo Lattes: http://lattes.cnpq.br/2212015109077386. Orcid: https://orcid.org/0000-0001-9871-4068. Email: monicatsribeiro@gmail.com

${ }^{2}$ Mestrado e Doutorado em Sociologia pela Universidade de Brasília (UnB). Professor do UniCEUB. Pesquisador do IPEA. Currículo Lattes: http://lattes.cnpq.br/2088412607903653. Orcid: https://orcid.org/0000-0001-8696-6153. E-mail: frederico.barbosa@ipea.gov.br. 
enchentes, produção de energia elétrica, irrigação e navegabilidade do rio, apresentando diversos significados que justificavam e enaltecem esses modelos de projetos. Contradito os relatórios governamentais, como resultado, percebeu-se a falta de mitigação dos impactos causados às comunidades ali existentes em educação, transporte, economia, saúde e independência. Ausentou-se do discurso as previsões de direitos, deveres e políticas públicas que seriam implantadas para que o desenvolvimento, enquanto liberdade, pudesse ser exercido em sua plenitude pelas pessoas que ali viviam. Percebeu-se uma ausência de participação e de investimento social e ambiental, não sendo possível dissocia-los, a confrontar o discurso de um período nacional desenvolvimentista a partir de políticas progressistas.

Palavras-chave: subjetividade; desenvolvimento; direito; acesso à justiça; políticas públicas.

ABSTRACT: The subjective perception of historical and social facts is reached from the local reality in traditional communities in the interior of Brazil. The city of Morada Nova de Minas is presented in this work under the narrative of the residents with the purpose of announcing what was lived from the occupation of the municipal lands by the waters dammed in the construction of the Três Marias dam. The field exploited is resinified when an independent and highly productive population, back to the use of lamps. The methodology of the use of semi-structured interviews is based on the reflection of the oral knowledge of the lived experiences and the importance of interpreting the facts under the oratory of a non-vocalized and alienated people. Large works have complex arguments as in this case, multiple purposes of containment of floods, electric power production, irrigation and navigability of the river, presenting several meanings that justify and extol these project models. Contrary to government reports, as a result, there was a perceived lack of mitigation of the impacts on existing communities in education, transportation, economy, health, and independence. The discourse left out the predictions of rights, duties and public policies that would be implemented so that development, as freedom, could be fully exercised by the people 


\section{ABDC Const}

who lived there. There was a lack of participation and social and environmental investment, and it was not possible to dissociate them, to confront the discourse of a national development period from progressive policies.

Keywords: subjectivity; development; right; access to justice; public policy.

\section{INTRODUÇÃO: DESENVOLVIMENTO E A CIDADE}

O presente artigo busca investigar através de dados estatísticos e de entrevistas a percepção do Moradores sobre a cidadania, sobre a realização de direitos sociais, inclusive os direitos de participação.

Compreender o contexto sócio histórico no qual se desdobra a percepção dos Moradenses, e que condiciona sentidos e significações a respeito dos direitos. Delimitar consensos e dissensos presentes nas narrativas orais a respeito de fatos históricos e do sentido da cidadania.

Esta investigação leva a sério a experiência e as narrativas dos entrevistados como parte dos contextos de produção de sentidos da cidadania. Procura, a partir das entrevistas, desenhar, em princípio, o quadro de produção de sentido no exercício dos direitos, elaborando quadro de referência que constroem significados sobre o que é viver e ter direitos em Morada Nova de Minas, interpretando relações de força simbólicas e de poder, no contexto de estruturações sociais, econômicas e culturais impactados pela barragem.

Os atores sociais vivenciam seu presente e estabelecem com sua contemporaneidade relações singulares, aderindo e fixando significados, distanciandose e aproximando-se a partir do material das experiências familiares e subjetivas. A história da chegada das águas inscreve-se nas dobras das narrativas, das memórias e do imaginário, o que faz com que os sujeitos não cessem de se interrogar sobre ela.

Não será estranho que os contemporâneos não cessem de se maravilhar com as realizações da época, que lhes parece pujante e, ao mesmo tempo sejam capazes da ironia e riso com a sua própria sorte ou má sorte histórica. Não nos esqueceremos de 
um fato simples, e os entrevistados não o permitem, que a história inscreve no imaginário relações de dominação e, portanto, não poderiam ser universais, expondo aqueles que se aproveitaram dos benefícios, foram pouco impactados objetiva ou subjetivamente, ou simplesmente seguiram o curso do inundamento, partindo para outros lugares, ajustando suas expectativas ou se adaptando às seguintes distribuições de direitos e riquezas.

O contexto de globalização, neoliberalismo e desenvolvimento são palavras ou conceitos que organizam diferentes narrativas ou explicações a respeito do mundo contemporâneo. Diferentes fenômenos estão associados a eles, mas uma ideia, especialmente, costura o mosaico e pode ser expressa em uma assertiva. As transformações técnico-científicas engendram profundas transformações nos regimes de produção, nos modos da cultura e nas cartografias dos desejos e das subjetividades. Dessa assertiva se desdobram outras associando aqueles conceitos.

A globalização refere-se às conexões cada mais intensivas dos territórios de produção, os bens são produzidos e circulam através das fronteiras nacionais e ritmos vertiginosos e as tecnologias potencializam esses processos de integração global de mercado e modos de fazer coisas e imaginários. O neoliberalismo refere-se a um conjunto de valores ético e morais que expressa projetos societários baseados nas liberdades individuais, no mérito pessoal e na desconfiança em coletivos, em especial aqueles agenciados pelo Estado, pela flexibilização de direitos e, em especial das relações de trabalho e das proteções às economias nacionais. As tecnologias oferecem recursos de ação antes impensados não apenas oferecendo oportunidades para o empreendedorismo individual, mas para estabelecer novos modos de sociabilidade negócios.

O desenvolvimento, quase por definição, relaciona-se com as possibilidades positivas abertas pelas tecnologias, seja pelas máquinas que permitiram a industrialização, pelas mídias ou pelas tecnologias digitais que conectam o mundo da produção e aumenta a produtividade do capital e do trabalho. As perspectivas da globalização, neoliberalismo e do desenvolvimento, de fato, representam possibilidades jamais vividas em nenhuma outra situação histórica. As possibilidades 
da tolerância cultural, da valorização do indivíduo, da ampliação progressiva e simultâneo enriquecimento da vida são inesgotáveis, mas também são limitadas por interesses e restrições à participação livre e igualitária.

Entretanto, no limite, essas transformações têm um lado sombrio. As tecnologias produzem desequilíbrios ecológicos, ameaçam formas de vida natural, de animais e plantas, geram perturbações, quando não exterminam modos culturais de vida, estimulando um tipo de consumismo destrutivo, tanto de recursos ambientais, quanto de formas de socialização e produção tradicionais. As vidas são resumidas a padrões e intensidades de troca intersubjetivas cada vez mais pobres e inexpressivas.

O Brasil atual tem cerca de 5.570 municípios. Todos os territórios são marcados por processos econômicos, social e culturais relacionados às interdependências localglobal de fluxos de produção e circulação de bens e mensagens, sendo impactados diferentemente nas suas formas de produção e consumo, socialização e relação com o meio ambiente. Morada de Nova de Minas é um exemplo das transformações tecnológicas. Sua história foi atravessada por ideais de desenvolvimento nacional e das mudanças de relacionamento da economia regional com projetos nacionais de inserção na economia global. A cidade foi fortemente impactada na década de 1960 pela construção da UHE (usina hidrelétrica) de Três Marias, que alterou o regime de águas do rio São Francisco com uma represa, transformando a paisagem natural e humana. O evento, uma escolha ideológica e política por um modelo de intervenção tecnológica sobre o meio ambiente, impactou fortemente nas relações sociais e nas subjetividades. Muitos anos se passaram, mas as imagens e redundâncias culturais ainda marcam fortemente as subjetividades e as estruturações sociais. Nesse artigo exploraremos a relação entre três registros diferentes, todos relacionados ao ecológico no município de Morada Nova de Minas: o meio ambiente, as relações sociais e as subjetividades, todos impactados pela barragem e hidrelétrica de Três Marias.

A primeira parte apresenta Morada Nova de Minas, a segunda apresenta a situação da cidade em números e a terceira apresenta as percepções subjetivas dos moradenses a respeito dos impactos da tecnologia de represamento e produção de energia. 


\section{MORADA E SUA HISTÓRIA - MAIS UM MUNICÍPIO}

Morada Nova de Minas é uma pequena cidade mineira, situada no centrooeste do estado de Minas Gerais. Assim como diversos municípios brasileiros, acompanhou e sofre transformações ao longo das últimas décadas em seus aspectos sociais, ambientais, econômicos, populacionais e nos seus padrões de desenvolvimento na sua forma mais ampla. As liberdades reais, isto é, nas possibilidades e capacidades de participação no conjunto das decisões, nas ações sociais e institucionais, bem como na organização dos serviços de saúde e educação, ambas associadas à participação mais geral nas atividades políticas como um todo.

Para contar a história da cidade foi realizado um recorte temporal com início na década de 60, quando o Brasil vivia o grande momento de expansão política e econômica, chamado de período nacional-desenvolvimentista. Nesta fase, os investimentos eram financeiramente altos e as propostas céleres: havia o anseio de inaugurar um novo Brasil e uma nova capital. Dentre os problemas a serem resolvidos estavam as enchentes que anualmente causavam alagamentos, mortes e diversos prejuízos de ordem pessoal, econômica e governamental.

A fim de conter as cheias, aproveitar o potencial hidroelétrico das águas e, expandir a agricultura irrigada, foi construída a barragem de Três Marias: a mais cara e maior obra nesse segmento à época. Contratou-se consultoria internacional, propriedade intelectual no uso de turbinas para implementação da obra inaugurada em 1962, criando a partir do barramento das águas, uma grande represa, que inundou metade do território de Morada Nova de Minas, ocupando especialmente as áreas de terras férteis.

O novo campo trouxe desafios diversos e um formato de vida ainda não experimentado por aquela comunidade: uso de lamparinas a substituir a energia elétrica que era fornecida com gerador próprio; uso de balsas para transporte nas áreas ilhadas antes acessadas por aterros que foram cobertos; uso de pivôs de irrigação para crescimento dos plantios em agricultura e cultivo; uso de novas formas de alimentar e colher os insumos, dada as alterações na fauna e na flora, além de criar uma nova 
linguagem nas narrativas históricas, a gerar mudança na forma de pensar e existir, a partir da transformação de comunidade emancipada que passa a viver em espaço carente de recursos.

Cenários foram alterados, refeitos e repensados nas políticas públicas de lá para cá. Fato que as pessoas vivem mais hoje do que viveram no passado e têm mais acesso à uma complexidade de informações pelo uso da tecnologia, maior oferta de meios de transporte e pela expansão dos bens de consumo aumentando a interação social. No entanto, para que a participação e uso das informações absorvidas seja um fato, é condição primária a existência de acesso à informação e educação para capacitação nos diálogos e decisões políticas a serem tomadas, saúde e saneamento básico para garantir a integridade física e consequente ao processo de participação, transporte e possibilidade de acesso a outros territórios, impedindo isolamento a fim de promover liberdade, desenvolvimento e inclusão nos debates.

Tais requisitos são essenciais o desenvolvimento, uma vez que a carência de oportunidades, de acesso aos serviços públicos ou ainda, a interferência excessiva de governos autoritários são fatores privativos da liberdade, e sem ela, não é possível pensar em desenvolver e expandir a vida plena. Trata-se, portanto, de condição basilar e precípua para esta temática. Somado a isso, acresce o fato de que foi à época da construção da barragem, construída também a maior rodovia do país: a BR040 como via de ligação entre a antiga capital, Rio de Janeiro, com a nova capital, Brasília, do qual os moradores não dispunham de acesso em razão da barreira criada pela água.

O acesso da população à BR040 tornou-se possível através de transporte fluvial, com o uso de balsas motorizadas para deslocamento de carros, pessoas, caminhões. As linhas férreas antes responsáveis pelo escoamento da produção, ficaram debaixo d'água junto com as fazendas, porteiras, cercas, animais, levando para o fundo da represa tudo aquilo que não se pôde salvar. A ausência de aviso prévio frustrou as expectativas de direito. Em contrapartida, órgãos federais teriam jogado bilhetes por meio de avião com aviso de que a água chegaria em julho daquele ano. Dados os fatos, percebeu-se ausência de preparo, ações ou políticas públicas para recepção da 
transformação somados às condições climáticas de um período chuvoso que acelerou a chegada das águas no mês de janeiro de 1962.

É relevante apresentar o projeto que construiu a barragem, tido a época como a grande obra do país. Onerosa, complexa e demorada, foi acompanhada de perto pelo então Presidente da República, Juscelino Kubitschek. A ausência de diálogo com os municípios atingidos chama atenção: tanto se investiu para a construção da obra por mais de cinco anos, mas nenhuma visita, projeto ou recurso foi destinado a esses locais previamente. A cidade de Três Marias, onde a barragem foi instalada, nasceu junto com a obra. A cidade de Morada Nova de Minas, já divisão administrativa há 19 anos³ foi reduzida à sua metade, perdeu recursos naturais, autonomia e independência.

Após a chegada das águas o governo enviou representantes técnicos de empresas públicas que apresentaram projetos de apoio e dialogaram com políticos locais - tal como hoje, enviando técnicos de obras - a realizar levantamentos sobre melhorias necessárias, contudo, atos posteriores à obra. Fazia-se para depois mitigar. A legislação atual exige análise profunda na aprovação de projetos de grande impacto. O texto constitucional à época não previa direitos sociais e ambientais, tratando-se de legislação oriunda de períodos autoritários de governo. Não é novo o uso de constituições por parte de governos ditatoriais: não cumprimento da legislação, desvio de interpretação constitucional e descumprimento às garantias fundamentais. Ressalvadas as distorções, sem a lei, não teríamos mais pobres, nem natureza, estariam todos dizimados.

Os relatórios governamentais realizados após a construção da barragem identificaram cenários favoráveis: boas condições geográficas, grande disponibilidade de uso de recursos hídricos favoráveis à mecanização agrícola, possibilidade de atrair empresas em razão da localização e o possível crescimento populacional dado

${ }^{3}$ Em 1852 , por Lei provincial $n^{\circ} 603$, foi criada a freguesia de Nossa Senhora do Loreto da Morada Nova. Elevado à categoria de município com a denominação de Morada, pelo DecretoLei Estadual $\mathrm{n}^{\mathrm{o}} 1058$, de 31-12-1943. IBGE, Disponível em $\langle$ https://cidades.ibge.gov.br/brasil/mg/morada-nova-de-minas/historico $>$ acessado em 29 de maio de 2019. 


\section{IIIIII \\ ABDCONST}

crescimento econômico da região. O que se viu, em verdade, foram conflitos agrários, desequilíbrio ambiental e evasão de espécies, isolamento, mobilidade humana forçada e ausência de participação política.

As decisões tomadas pelo governo ao longo da história, a respeito da oferta hídrica, suas políticas e ações foram criticadas desde sempre pela arbitrariedade e desrespeito à legislação: o poderio econômico como prioridade, criou uma série de miseráveis ao longo do rio São Francisco. Ribeirinhos dependentes de políticas públicas foram esquecidos e marginalizados, famílias foram separadas e o êxodo forçado marcou início do apagamento cultural, perda de identidade e alienação ${ }^{4}$ da população.

Os processos de desapropriação originaram especulação imobiliária e consequente manutenção de posses de terras por apenas uma empresa que não gerou os empregos esperados. Além disso, não foi efetivada indenização justa pelas perdas de terras. A difícil comunicação à época, distância geográfica e difícil acesso à região, gerou dependência de terceiros para intermediar diálogos entre governo federal - há cerca de $650 \mathrm{~km}$ de distância - e advogados residentes em municípios diversos que defendiam os interesses dos moradores do local.

As alterações na dinâmica local transformaram a história da cidade, das pessoas e de suas expectativas: antes, haviam sonhos de crescimento e escolhas. A partir da chegada das águas, a derrota econômica e social inverteu tudo que já havia sido conquistado: uma população emancipada, tornou-se alienada, dependente e sem identidade, registros essenciais para discernir a internalização de sujeitos de direito e acesso à justiça, emancipação e participação social nos processos de desenvolvimento.

${ }^{4} \mathrm{O}$ uso do termo alienação refere-se à impossibilidade de desenvolvimento humano integral, em decorrência da manipulação ideológica e da impossibilidade de participação em situações de interesse existencial. Refere-se às relações de dominação simbólica, assimetria de poder e de não reconhecimento da legitimidade social. 
3. O QUE DIZEM OS NÚMEROS: ESCOLARIDADE, RENDA E DESENVOLVIMENTO

As mutações tecnológicas disponibilizaram possibilidades múltiplas para a reorganização dos modos de produzir e viver. Os grandes projetos hidrelétricos marcam ainda hoje as alternativas de produção de energia para as indústrias e para irrigar a vida urbana. As grandes hidrelétricas ainda proliferam no território nacional gerando impactos ambientais, sociais e subjetivos. Trata-se de empreendimentos que transformam o ambiente e as relações sociais. Ademais, é necessário lembrar que a mudança de regime dos rios, além de impactar fortemente o meio ambiente e a vida animal e vegetal, altera o regime de chuvas e microclimas com impactos globais. Minas Gerais é um estado especialmente vulnerável por ter conectado esses múltiplos sistemas à exploração de minérios. Os rios e seus sistemas ecológicos foram e estão potencialmente expostos há décadas ao colapso ambiental.

Os impactos da barragem foram definitivos e contraditórios. A ideia dos grandes projetos é de intervenção massiva no meio ambiente e na vida social, gerando perdas e desigualdades. O isolamento de Morada Nova de Minas pelo corte de suas ligações mais diretas causou dependência do sistema de transporte por meio de barcos, em termos de possibilidades de ligação por meio de transporte e vias terrestres, levou a uma profunda rearticulação de estratégias sociais. O movimento populacional foi deixar a cidade para buscar meio de vida, trabalho e esperança através da migração. A perda populacional explica os indicadores sociais do município, a respeito dos quais trataremos adiante. Impossível nesse caso estabelecer nexos causais muito precisos. Se não se pode afirmar que conflitos desse tipo, isto é, ambientais e culturais, substituíram de forma mecânica os conflitos de classe, é possível dizer que eles já constituem em mediadores centrais que colocam políticas públicas setoriais no centro de visibilidade das lutas sociais. Contudo, vamos acrescentando camadas à nossa descrição. Em primeiro lugar, é preciso dizer que a composição social é diversa.

A descrição do perfil socioeconômico é reveladora das estruturações que condicionam processo de subjetivação. Classes salariais, a massa de "não garantidos" 


\section{-

e camadas dirigentes marcam processos de subjetivação específicos. A população de Morada é constituída por $31 \%$ de trabalhadores nos serviços, $29 \%$ de pessoas ligadas à agricultura, $25 \%$ de trabalhadores e $12 \%$ nas classes criativas, considerando que essa última, em parte, compõe a classe de serviços, mas dela se afastando pela presença de maior escolarização. As classes criativas incluem atividades no âmbito das culturais e artes, saúde, educação, direito e profissões gerencias.

No que se refere aos indicadores sociais, eles expressam movimentos do sistema de proteção e de políticas sociais. Resultam do conjunto de ações econômicas, então o PIB tem uma participação importante nas distribuições e depois nas possibilidades de prestações públicas de serviços sociais tais quais saúde, educação, assistências social e previdência, da mesma forma que as transferências constitucionais obrigatórias e as políticas federais e estaduais também impactam nas prestações das políticas sociais locais. Como essas políticas preveem sistema de conselhos, é provável que estimulem a participação social nesses diferentes espaços institucionais. Entretanto, por mais importantes que sejam, essas políticas compensatórias apenas mitigam o imenso sistema de produção de fome, pobreza, desemprego, isolamento e vulnerabilização social condicionando processo de subjetivação. Outras clivagens relevantes não serão exploradas aqui, a exemplo de questões de desigualdades de gênero e questões relacionadas à juventude, com suas demandas por escolarização e profissionais e os idosos, com suas necessidades de proteção e cuidados. Rapidamente pode-se dizer que as relações de gênero são tradicionalistas e que a juventude se digladia com a questão da escolarização e permanência ou não na cidade em função, inclusive, da existência de oportunidades de educação e trabalho. O IDH é um indicador sintético para o qual convergem economia (PIB), educação e saúde. Embora as ações políticas no terreno da implementação não sejam necessariamente transversais, como poderia sugerir o uso de indicador sintético de múltiplos fenômenos associados, pode-se dizer que, de fato, configuram ou expressam ideias de direito ou justiça das prestações públicas. Os indicadores sintéticos, por sua vez, expressam de forma apenas relativamente precisa a resultante do desempenho daquelas dimensões da realidade institucional, ou seja, de capacidades institucionais. Muitos elementos de 


\section{IIIIII \\ ABDCONST}

contexto são abstraídos, mas deve-se enfatizar interdependência das escalas individuais e coletivas do cotidiano e nos processos institucionais das democracias. Não se pretende que questões de justiça social como aquelas descritas pelos indicadores aqui apresentados encabeçam todas as outras, mas que são um bom termômetro para medir distribuições e capacidades e, de forma próxima, questões do tipo de democracia presente. Assim como palavras de ordem expropriam a complexidade dos fenômenos distributivos e relacionais, abstraindo o racismo, falocentrismo, logocentrismo etc., os indicadores podem, ao serem tomados em si mesmo, criar interpretações estereotipadas e reducionistas. Voltaremos mais à frente às subjetividades, para retomar em parte, uma interpretação ampliativa, assim articulando uma perspectiva geral, objetivista, de escala institucional maior e outra singular, microssocial e subjetivista. As duas dimensões devem ser consideradas em conjunto e se encarnam em micropolíticas concretas, não compartimentadas, transversais, características pouco afeta à tecnoburocracia estatal ou aos oportunistas dos mercados, capazes de capitalizar a produção simbólica, de signos e informações.

Morada Nova de Minas fica na mesorregião Central Mineira, na microrregião de Três Marias, situa-se a 280 km de Belo Horizonte, tem $2.084,612 \mathrm{~km}^{2}$ e pouco mais de 8.200 habitantes. Seu IDHM é alto, ou seja, de 0,76 (ver Tabela 1). As receitas de Morada Nova de Minas foram de R\$ 29.000.000, em 2018, sendo que aproximadamente $85 \%$ é de transferências e $93 \%$ é de encargos e pessoal. As despesas giraram em 2018 em torno de R\$ 32.380 mil em saúde e educação, o que significa algo em torno de $40 \%$ das despesas ou $23,7 \%$ e $16,3 \%$, respectivamente. Transporte hidroviário representou 6\% das despesas (aproximadamente R 2 milhões).

Apenas para termos um quadro geral comparativo apresentamos a tabela seguinte com dados comparáveis construídos a partir dos Censos Demográficos de 2000 e 2010. As populações dos municípios que constituem a Região Central Mineira são diminutas, a própria região sendo constituída por 412 mil pessoas, portanto de tamanho aproximado a município de médio porte. O Estado de Minas Gerais tem 19,5 milhões, a RM Belo Horizonte tem 6,2 milhões, a RM Três Marias tem quase 97 mil 
habitantes, sendo que o município tem 28 mil, depois de Pompeu que tem 28 mil habitantes. Morada tem, em 2010, 8.255 habitantes.

As taxas de desemprego no Brasil eram de 7,6\%, de Minas 6,7\%, da Central Mineira 6,9\%, da RM Belo Horizonte 7,4\%, de Três marias 8,5\%, Felixlândia e Cedro do Abaeté tinham taxas d desemprego acima de 9\%, enquanto Morada Nova tinha taxa de desemprego de $3,2 \%$.

O percentual de pobres em Morada Nova era de 2,6\% em contraste com os demais municípios, com taxas sempre superiores a 3\%, chegando em Três Marias a 4,9\% e até a 6,4\% em São Gonçalo do Abaeté.

Tabela 1

Indicadores socioeconômicos selecionados

\begin{tabular}{|c|c|c|c|c|c|c|}
\hline $\begin{array}{l}\text { Brasil, Sudeste, Minas gerais, Meso região, micro-região e municípios } \\
\text { selecionados }\end{array}$ & $\begin{array}{c}\text { Taxa de } \\
\text { desemprego } \\
\text { (2010) }\end{array}$ & $\begin{array}{c}\text { Pobres (\%) } \\
\text { (2010) }\end{array}$ & PIB(2009) & $\begin{array}{c}\mathrm{IDH}(2000) \\
\left({ }^{*}\right)\end{array}$ & $\begin{array}{c}\text { IDH } \\
\text { Longevidade } \\
(2000) \\
\left({ }^{*}\right)\end{array}$ & $\begin{array}{l}\text { IDH Educação } \\
(2000) \\
(*)\end{array}$ \\
\hline Brasil & 7,65 & 9,38 & 1.564.354.790 & 0,77 & 0,73 & 0,85 \\
\hline Sudeste & 7,54 & 5,35 & 865.406 .412 & - & - & - \\
\hline Minas Gerais & 6,79 & 5,31 & 138.622.865 & 0,77 & 0,76 & 0,85 \\
\hline 3106 - Central Mineira & 6,89 & 3,64 & 2.330 .601 & - & - & - \\
\hline 3107 - Metropolitana de Belo Horizonte & 7,40 & 4,04 & 59.948 .326 & - & - & - \\
\hline 31024 - Três Marias & 6,33 & 3,93 & 804.958 & - & - & - \\
\hline 3143500 - Morada Nova de Minas & 3,27 & 2,60 & 37.086 & 0,76 & 0,82 & 0,82 \\
\hline 3107000 - Biquinhas & 3,05 & 3,82 & 12.431 & 0,75 & 0,79 & 0,81 \\
\hline 3115607 - Cedro do Abaeté & 9,07 & 4,21 & 4.936 & 0,75 & 0,81 & 0,80 \\
\hline 3125705 - Felixlândia & 9,20 & 4,88 & 70.764 & 0,73 & 0,76 & 0,82 \\
\hline 3152006 - Pompéu & 6,50 & 4,24 & 187.286 & 0,75 & 0,74 & 0,81 \\
\hline 3161700 - São Gonçalo do Abaeté & 4,30 & 6,43 & 47.465 & 0,74 & 0,76 & 0,82 \\
\hline 3169356 - Três Marias & 8,50 & 4,90 & 428.201 & 0,79 & 0,81 & 0,88 \\
\hline
\end{tabular}

(*) IPEADATA

Elaboração dos autores

Desde o século de XVI há registros de construções de barragens no Brasil, iniciadas no Sudeste e posteriormente implementadas ao longo dos rios que correm o país em diversas regiões.

Os mecanismos de proposição de projetos complexos que acompanharam as formas de governo e a legislação vigente à época, têm em comum traços de autoritarismo e ausência de participação popular nos processos decisórios, que mesmo após a promulgação de direitos civis e políticos negligenciam requisitos de consulta prévia, participação popular e previsão de impactos ambientais para outorga de licenciamento. 
É importante historicizar as tecnologias e as opções políticas no seu uso, mas é necessário lembrar que sempre existiram alternativas tecnológicas, mas que as escolhas são orientadas ideologicamente, em muitos casos em descuido evidente de questões ambientais e sociais. $\mathrm{O}$ quadro 1 mostra projetos hidrelétricos e a racionalidade relativa estabelecida entre área alagada e potência.

Quadro 1

\begin{tabular}{|c|c|c|c|c|c|c|}
\hline UHE & Estado & Proprietário & $\begin{array}{l}\text { Ano } \\
\text { operação }\end{array}$ & Tecnologia & $\begin{array}{l}\text { Área } \\
\text { alagada }\end{array}$ & Potência \\
\hline TRES MARIAS & MG & Cemig & 1962 & $\begin{array}{l}\text { Reservatório } \\
\text { convencional }\end{array}$ & $\begin{array}{l}1.040 \\
\mathrm{~km}^{2}\end{array}$ & $396.000,00$ \\
\hline ITAIPU & PR & $\begin{array}{l}\text { Itaipu } \\
\text { Binacional }\end{array}$ & 1989 & $\begin{array}{l}\text { Reservatório } \\
\text { convencional }\end{array}$ & $\begin{array}{l}1.350 \\
\mathrm{~km}^{2}\end{array}$ & $7.000 .000,00$ \\
\hline TUCURUI & PA & Eletronorte & 1984 & $\begin{array}{l}\text { Reservatório } \\
\text { convencional }\end{array}$ & $\begin{array}{l}2.850 \\
\mathrm{~km}^{2}\end{array}$ & $8.535 .000,00$ \\
\hline EMBORCAÇÃO & GO/MG & Cemig & 1982 & $\begin{array}{l}\text { Reservatório } \\
\text { convencional }\end{array}$ & $\begin{array}{l}473 \\
\mathrm{~km}^{2}\end{array}$ & $1.192 .000,00$ \\
\hline XINGÓ & AL/SE & CHESF & 1994 & $\begin{array}{l}\text { Reservatório } \\
\text { convencional }\end{array}$ & $60 \mathrm{~km}^{2}$ & $3.162 .000,00$ \\
\hline $\begin{array}{l}\text { SERRA } \\
\text { MESA }\end{array}$ & GO & FURNAS & 1998 & $\begin{array}{l}\text { Reservatório } \\
\text { convencional }\end{array}$ & $\begin{array}{l}1784 \\
\mathrm{~km}^{2}\end{array}$ & $1.275 .000,00$ \\
\hline $\begin{array}{l}\text { LAJEADO - Luís } \\
\text { Eduardo } \\
\text { Magalhães }\end{array}$ & TO & $\begin{array}{l}\text { CEB- } \\
\text { Lajeado }\end{array}$ & 2001 & $\begin{array}{l}\text { Reservatório } \\
\text { convencional }\end{array}$ & $\begin{array}{l}630 \\
\mathrm{~km}^{2}\end{array}$ & $902.500,00$ \\
\hline JIRAU & RO & $\begin{array}{l}\text { Energia } \\
\text { Sustentável } \\
\text { do Brasil } \\
\text { S/A }\end{array}$ & 2013 & Fio d'água & $\begin{array}{l}361,6 \\
\mathrm{~km}^{2}\end{array}$ & $3.750 .000,00$ \\
\hline BELO MONTE & $\mathrm{PA}$ & $\begin{array}{l}\text { Norte } \\
\text { Energia S/A }\end{array}$ & 2016 & Fio d'água & $\begin{array}{l}516 \\
\mathrm{~km}^{2}\end{array}$ & $11.233 .100,00$ \\
\hline
\end{tabular}

Fonte: Agência Nacional de Energia Elétrica - ANEEL

Elaboração dos autores 


\section{.

Comparados alguns projetos, é possível diagnosticar - mesmo em barragens com recursos tecnológicos semelhantes - a diferença entre a energia elétrica produzida com o tamanho da área alagada. Este é um dos requisitos para trazer à tona a justificativa do grande prejuízo causado pela área ocupada pelas águas represadas na UHE (usina hidrelétrica) de Três Marias, cuja potência de geração de energia é ínfima diante dos prejuízos causados. Numa justificativa de que eletricidade não era o objetivo único - mas também o controle das cheias - relatórios e uma Comissão de Inquérito Parlamentar ${ }^{5}$ foi instaurada a apurar a não contenção das cheias, mortes e desequilíbrio ambiental, além do desamparo às comunidades ribeirinhas, causando colapso nas áreas afetadas.

A produção de energia elétrica no Brasil ainda é dependente de recursos hídricos, ao passo que mais de $80 \%$ é gerado a partir das usinas hidroelétricas. As implantações mais recentes dispõem de reservatório menores e menor potencial poluente, ao usar a tecnologia "fio d'água", que também cria usa o represamento como técnica, mas sem grande estoque de água, usando a força da correnteza do rio para produção $^{6}$. A disponibilidade para a produção é reduzida à quantidade de água semanal uma vez que não há estoque de água, fato que reduz ou impossibilita a produção de energia em períodos de estiagem. Outro fator negativo é a quebra do ciclo reprodutivo de peixes, criando um ambiente inóspito ou impossível para a vida aquática.

Outro impacto relevante causado na vida humana e na natureza é o controle do fluxo da água por empresas privadas ou órgão governamental. Enquanto as populações locais estão acostumadas a acompanhar o curso das águas através do ciclo natural dos períodos de cheia e seca, passam a depender dos interesses governamentais e suas

5 BRASIL, Câmara dos Deputados, Projeto de Resolução de Comissão Parlamentar de Inquérito Destinada a Investigar as Causas e Consequências das Cheias do Rio São Francisco. Prisco Viana: no exercício da Presidência. Elquisson Soares: Relator. Sala de Sessões. Brasília, 22 de outubro de 1981.

6 ANEEL. Resolução normativa $\mathrm{n}^{\circ} 425$ de 1/2/2011: Disponível em <http://www2.aneel.gov.br/cedoc/ren2011425.pdf > acessado em 01 de maio de 2019. 


\section{IIIIIII \\ ABDCONST}

decisões unilaterais para reduzir ou aumentar a evasão de água. Nas linhas da história contada pelos relatórios e monografias governamentais, muito pouco ou quase nada é dedicado aos povos que habitam as regiões alagadas. As reuniões preparatórias para implementação de grandes obras não constam a participação e a vocalização de demandas dos ribeirinhos, dos povos locais e tradicionais que comumente habitam as regiões escolhidas para a construção de obras dessa categoria. A chegada de movimentos populares que legitimam e cobram a presença popular nesses espaços, ainda é deslegitimada por discursos de sobrepostos interesses como o bem maior de todos, crescimento econômico, geração de empregos dentre outras promessas não cumpridas.

O que se vê na prática, é a perda de trabalho, mudança de vida pela ausência de espaços para plantio, apropriação do Estado pelos recursos naturais que antes eram fonte de trabalho: altera-se a vida organizada em torno da natureza, por promessas de indenização pecuniária, casas e cestas básicas. A sabedoria popular, a forma de vida através das técnicas de uso do rio com a pesca, a plantação e períodos de colheita, são absortos por discursos desenvolvimentistas e economicistas a preterir o desenvolvimento humano: a manutenção de povos tradicionais, sua cultura, os saberes locais e a vida em contato e respeito ao tempo da natureza, ao curso natural das águas e ainda, ao potencial de independência dos beiradeiros, aqueles que nascem e vivem nas beiras dos rios. É possível, para o ser humano acostumado a trabalhar e ter sentido em sua vida cotidiana, aposentar-se compulsoriamente e ocupar seu tempo em se alimentar de cesta básica? Para dar significado à vida, além de trabalho é preciso a oportunidade de escolhas, participação das decisões sobre os caminhos da manutenção cultural de uma vida conectada à natureza quando esta faz parte de seus hábitos.

A violência acomoda-se em locais como estes, que são ocupados por milhares de trabalhadores de regiões diversas do país em busca de emprego e nova vida. Disputa por espaços, controle de comércios e respeito à comunidade ali existente são alguns dos conflitos existentes, a partir da chegada de novas propostas de crescimento econômico. O fato de o Brasil estar atualmente entre os 10 maiores consumidores de energia do mundo, sendo o maior consumidor da América do Sul está diretamente 


\section{.

ligado à exploração dos recursos hídricos para a produção desta fonte geradora, que afeta negativamente milhares de brasileiros retirados de suas casas sob a justificativa de crescimento econômico. O crescimento de pobres e miseráveis está ligado a este fato, uma vez que a concentração de riquezas está numa minoria crescente sob a pirâmide erguida pelo decréscimo de autonomia de uma maioria invisível. Entretanto, a relação não é linear. Como se viu os indicadores socioeconômicos são variados dentro da mesma região. O fenômeno é complexo, os indicadores recobrem apenas parte da realidade. Por essa razão se fez entrevistas com moradores que viveram o processo de alagamento decorrente da barragem.

Em geral, as informações subjetivas são menosprezadas pela falta de precisão. Entretanto, as entrevistas, histórias de vida e percepções oferecem informações importantes que explicam ou contextualizam os indicadores. Como o nosso foco é ideia de desenvolvimento como liberdade, questão implicitamente explorada com o IDHM, já que Amartya Sen elaborou o indicador (IDH) exatamente para expressar pujança econômica (PIB) e seus efeitos sobre a saúde e educação e vice-versa, nos perguntamos pela participação nos processos de planejamento, elaboração e implementação da obra de grande vulto em Três Marias. É surpreendente o descaso com a questão ambiental e a verticalidade da implementação do projeto. Antes de explora as entrevistas, cabe algumas considerações metodológicas sobre entrevistas

\section{PERCEPÇÕES SUBJETIVAS DOS MORADENSES}

\subsection{AS ENTREVISTAS: ARTEFATOS METODOLÓGICOS}

A preparação para as entrevistas exige memória e, de preferência, uma listinha. Questões preparadas, consentimento, data na agenda, caderno de anotações, caneta ou lápis, gravador ou se se preferir, celular, para registrar o encontro, pelo menos em algumas das suas partes; entre as anotações - não se esquecer de registrar - para bom uso na entrevista são necessárias generosidade, dedicação, capacidade de escuta, argúcia (para os que a têm) etc. Tantos são os indexadores que adjetivam ou 


\section{IIIIII \\ ABDCONST}

descrevem as disposições necessárias às redes de conversas que constituem as entrevistas.

Os preparativos para as entrevistas envolvem volição e a presença corporal, as disposições próprias para a conversa, boas questões e habilidades para contornar as ruins, alguma capacidade de controlar as situações inesperadas, a incomunicabilidade e a incompreensão mútua, a confusão da escola, as assimetrias de informação e posição, sendo a própria entrevista uma relação delicada, onde são mobilizadas seguranças e inseguranças. A conversa é embalada por sorrisos e pequenos desentendimentos, escuta atenta, esquecimentos, algumas diminutas invenções e digressões. Sem ilusões. A entrevista não é uma conversa descontraída. Não se pode adivinhar o outro e, nem da parte dos entrevistados, os usos possíveis ou prováveis do que se fala. Será que é possível imaginar que a escrita será realizada sobre lembranças frágeis e difusas, apontamentos em letras ilegível e sínteses impossíveis?

Entretanto, ficam nas gravações as falas, pausas, titubeios, silêncios, se perdem os movimentos, gestos, olhares, desvios. A impressão de que as falas têm valor irredutível, de que os enunciados expressam o que acontece, aconteceu e que a referencialidade é incontrovertida. É como se não fossem os enunciados parte de uma rede de enunciados seletivos, escolhidos, valorados e como se as narrativas sobre eles não fossem enunciadas sobre enunciados, traduções, reduções, sobre as quais é necessário por pontos, vírgulas, pontos-vírgulas, assinalar tons, ênfases.

$\mathrm{Na}$ escrita, grande parte da seleção envolve o que é gramatical, nada de oralidades, risadas, balbúrdias, cortes no fluxo das respostas ou perguntas, falas atravessadas, ..., também ficam as grandes questões que serão destrinchadas, analisadas, sintetizadas, reinventadas, traduzidas, reinterpretadas, deslocadas, transloucadas, citadas, inseridas, resumidas, desdobradas, torcidas. Em muitas situações, as entrevistas confirmam, corroboram, reforçam, fazem o campo e constroem o contexto alusivo, afirma que estivemos lá, que vimos, ouvimos, até tocamos e sentimos os cheiros.

A entrevista é testemunhal. Atribui, assim, valor irredutível à verdade a ser dita, seja ela qual for, mas à qual se conferirá valor demonstrativo. Na escrita, são muitas as 
presenças feitas de ausências e esquecimentos, escolhas a respeito do que será apresentado. É possível perceber os rastros, mas há sempre traições e colonizações. Imprecisões apenas possíveis no apagamento da presença e do rosto de quem foi entrevistado. A dívida é impagável, a não ser se saldada em outra moeda de troca, com a escrita dos diários, gravação, materiais, publicações e sobretudo de reconhecimentos.

As entrevistas dão voz, escutam, reconhecem presenças e singularidades, mas não daremos nomes. Separamos temas e respostas a questões elaboradas previamente. Vamos às narrativas coletadas nas entrevistas.

\subsection{AS ENTREVISTAS}

A narrativa é uma importante ferramenta de expressão cultural da história vivida e da produção de identidades pessoais, sociais e territoriais. Os moradores da cidade de Morada Nova de Minas compartilham experiências e se identificam nas narrativas comuns. Alguns viveram, outros escutaram estórias da subida das águas. Entretanto, as narrativas apresentam diferentes camadas que entrelaçam memória, julgamento, crítica, sabedoria, avaliação moral e política.

A "chegada das águas" e Morada Nova de Minas teve algo que pode ser retratada como violência simbólica. Talvez a "chegada das águas" tenha um uso metafórico, talvez seja uma síntese de uma série relações estruturadas: ausência de planejamento, ausência de participação e comunicação adequada entre poder público e sociedade. Alguns dos entrevistados lembram da pressa e da ausência de tempo adequado à preparação para a retirada das pessoas, coisas e animais; alguns lembram das prováveis intenções, razões para o açodamento. Entretanto, todos lembram-se bem da pressa e ausência de preparativos, avaliam o que era Morada e o que se tornou, as mudanças, com suas perdas e ganhos históricos, as relações com o Estado, ou melhor, com o direito a ser indenizado. O balanço das entrevistas é o da existência de uma série de controvérsias, de um senso crítico, mas também de profunda capacidade de adaptação às situações e desafios sociais.

Um último ponto. Sabemos que as entrevistas não dizem "coisas" em si mesmas. Futuramente serão necessárias discussões e interpretações mais ousadas sobre 


\section{IIIIIIII \\ ABDCONST}

o que ouvimos. Entretanto, organizamos as entrevistas em domínios temáticos. Eles se misturam e remetem uns aos outros. Nossa escolha aqui é de dar a voz. Passemos a que ouvimos ${ }^{7}$ :

\subsection{A PRESSA E A AUSÊNCIA DE PREPARATIVOS}

A: E como! Caminhões e caminhões com mudança. A prefeitura ajudando nesse aspecto, as pessoas, umas revoltadas, outras nem tanto. Mas saindo... Eu me lembro que para a chegada das águas não houve preparativo nenhum, praticamente. Não houve postura ecológica em que as espécies fossem preservadas. Então muitos animais perderam-se. Então as enchentes, a violência das águas, e praticamente muitas plantas também se perderam, espécies que até hoje não existem mais. Foi um desastre ecológico podemos dizer assim. Além da dinâmica da cidade, afetou muito. Porque a população diminuiu muito e ficou aqueles que eram persistentes, mais ou menos isso.

C: Quando a água chegou foi assim um desespero, sabe? A estrada que a gente ia e voltava, foi tomada, ne? Aí nós tivemos que passar pelo rio, pela represa. Passamos numa canoa. Não tinha essa passagem normal, sabe? Eu lembro que eu morria de medo. Tive assim, já começou a sensação, né? Quando eu vim já começou a sensação ruim. Depois cheguei aqui, pessoal todo desesperado, uns tiveram que mudar correndo. Aqui na fazenda, pessoal saiu todo, teve que mudar. Tinha muita gente que morava aqui, foi todo mundo embora. A gente sentiu, sabe assim? Uma sensação muito ruim quando encheu. Não tinha nada bom. Não vimos nada de bom. Só coisa triste. Depois foi ajeitando, né? Fizeram os portos, as estradas. Mas no início foi terrível.

L: Eu morava nos mateiros, quando essa água subiu. Nos vinha na beira do indaiá aqui, pesca esses "trem" aí, eu mais meu pai. Depois veio a água e nos mesmos, um dia nos ajudamos a tirar uns milhos das roças. A represa estava subindo, mas

\footnotetext{
${ }^{7}$ Identificamos os entrevistados por letras.
} 


\section{- \\ ABDCONST}

estava subindo igual leite. E nos catando milho e pondo dentro da canoa. Quebrando e pondo dentro da canoa. Minha filha do céu, mas você nunca viu o tanto que é ficar estragado. Com tanta formiga nos milhos (risos).

$\mathrm{W}$ : Porque ele $[\mathrm{JK}]$ tomou conhecimento que o supremo ia conceder a liminar. Mas aí ele inaugurou rápido porque ele soube que o supremo ia atrapalhar essa decisão.

\subsection{MEMÓRIA: O QUE ERA E O QUE SE TORNOU MORADA}

A: E como! Caminhões e caminhões com mudança. A prefeitura ajudando nesse aspecto, as pessoas, umas revoltadas, outras nem tanto. Mas saindo... Eu me lembro que para a chegada das águas não houve preparativo nenhum, praticamente. Não houve postura ecológica em que as espécies fossem preservadas. Então muitos animais perderam-se. Então as enchentes, a violência das águas, e praticamente muitas plantas também se perderam, espécies que até hoje não existem mais. Foi um desastre ecológico podemos dizer assim. Além da dinâmica da cidade, afetou muito. Porque a população diminuiu muito e ficou aqueles que eram persistentes, mais ou menos isso.

C: Quando a água chegou foi assim um desespero, sabe? A estrada que a gente ia e voltava, foi tomada, ne? Aí nós tivemos que passar pelo rio, pela represa. Passamos numa canoa. Não tinha essa passagem normal, sabe? Eu lembro que eu morria de medo. Tive assim, já começou a sensação, né? Quando eu vim já começou a sensação ruim. Depois cheguei aqui, pessoal todo desesperado, uns tiveram que mudar correndo. Aqui na fazenda, pessoal saiu todo, teve que mudar. Tinha muita gente que morava aqui, foi todo mundo embora. A gente sentiu, sabe assim? Uma sensação muito ruim quando encheu. Não tinha nada bom. Não vimos nada de bom. Só coisa triste. Depois foi ajeitando, né? Fizeram os portos, as estradas. Mas no início foi terrível.

L: Eu morava nos mateiros, quando essa água subiu. Nos vinha na beira do indaiá aqui, pesca esses “trem” aí, eu mais meu pai. Depois veio a água e nos mesmos, um dia nos ajudamos a tirar uns milhos das roças. A represa estava subindo, mas 


\section{$-\pi$ \\ ABDCONST}

estava subindo igual leite. E nos catando milho e pondo dentro da canoa. Quebrando e pondo dentro da canoa. Minha filha do céu, mas você nunca viu o tanto que é ficar estragado. Com tanta formiga nos milhos (risos).

$\mathrm{W}$ : Porque ele $[\mathrm{JK}]$ tomou conhecimento que o supremo ia conceder a liminar. Mas aí ele inaugurou rápido porque ele soube que o supremo ia atrapalhar essa decisão.

\subsection{MEMÓRIA: O QUE ERA E O QUE SE TORNOU MORADA}

A: É meio complicado porque, as diferenças entre as duas etapas são enormes. Antigamente, antes da chegada das águas, nós vamos ver uma cidade impulsionada por progresso. Muito dinâmica com a criação de gado muito efetiva, muito acentuada. E depois as águas, uma decadência absurda. Em época em que o povo perdeu a autoestima e era muito sofrido, sem ânimo para novas construções novos projetos, entendeu?

A: Antes da água, como é que diz, era bom, a senhora sabe porquê? Porque todo mundo, os fazendeiros, tinha as áreas do rio que a gente plantava roça. Depois a água veio tomou conta. Deus abençoou que eles arrumaram esses pivôs, planta no mato, e deus abençoou que colhe, né. Pra gente comer. A água então trouxe muita fartura de peixe. Antigamente, era tudo muito difícil. Era falta de dinheiro, de um pão. A gente trabalhava para morrer. Tinha dia que só tinha uma pedra de sal para fazer mistura. Tinha muito fazendeiro, mas era tudo ruim. Era tudo ruim demais, eu estava falando isso com o Sr. Chico. Hoje, não. Hoje eu vou na vizinha e se ela precisa, eu levo um pouco de arroz, um óleo, açúcar. Antes não tinha essa fartura.

D: Eu lembro de Morada, era triste. Morada era muito triste, não tinha luz. Era puro barro. Não tinha água, só existia uma torneira na esquina assim e tinha horário de abrir a água, né? Só depois que Dr. Walter aposentou da BMG e candidatou, foi ai que a vida da gente começou a melhorar.

I: Nossa o pessoal ficou muito triste, todo mundo reclamando. Porque melhorou muito para o país, mas morada ficou lá, devastada. I eles sabiam que ia chegar, porque 


\section{- \\ ABDCONST}

papai toda vida assinou jornal. Eles sabiam. Mas não naquela época. Era junho que ia fechar as comportas. Mas aconteceu que choveu demais no mês de janeiro. Choveu que foi uma coisa absurda. E a água subiu sem eles esperarem. Invadiu as fazendas, as plantações de milho, feijão. O povo ia vender, mas ninguém tinha tirado nada. Aí papai me chamou para dar uma volta a cavalo. E eu lembro direitinho, só a ponta do milho, E eu vi, tudo debaixo da água, tudo. Muita terra debaixo da água.

$\mathrm{N}$ : A água veio "praqui” porque eles fizeram a barragem de Três Marias, ne? Aí cercou a água aí a represa encheu. Por um lado, foi muito bom, mas por outros foi ruim. Encheu de água, pro lado dos pescadores foi muito bom, porque a fartura d'agua é boa, né? Mas quando era, que não tinha represa, de repente era melhor. O povo tocava lavoura na beira do rio. Plantava feijão, arroz, milho. Era muita fartura.

W: Inicialmente na época, nós pensávamos isso. Que foi uma violência de JK. Inclusive entrou na justiça, o supremo. E o supremo deu uma liminar para abrir as comportas. Mas não podia mais. A comporta não tinha mais condição de subir. Técnica. Condição técnica. De forma que nós tivemos nossas terras inundadas, e foi uma época de muita chuva. Um ano de muita chuva e foi no máximo a represa.

\subsection{AS PERDAS E OS GANHOS}

A: Lembro. Ele contava muita história. Ficou fazenda debaixo d'agua. Ficou até panela. Tem uma que eu pajeio ela até hoje, mas eles...não... O Nego que me contava mais história, quando a gente ia andar a cavalo. Muita fazenda ficou debaixo d'agua.

L: Elas ficaram desorientadas, precisavam mudar. Não sabiam para onde iam. Isso eu lembro. Muitos agregados nossos, lá da nossa fazenda, falavam: agora pra onde que a gente vai? Aqui é a fazenda maior, as outras são pequenas não tem trabalho. Eu lembro que eles falavam isso.

C: Mesmo assim, porque a cultura e a fartura que era. Eram caminhões e caminhões de milho, feijão. Cheio, tudo produzido aqui. E acabou tudo, não tinha mais nada. 


\section{.

I: [quando a água chegou] Acabou. Ficou tudo debaixo da água. Acabou. Ficou. O gado ficava lá, ne? Eu tinha um tio que ficava lá no rancho, e olhava. No mesmo lugar. Ficou intacta as pastagens. Teve problema não. A população de Unaí fícou aumentada. João Pinheiro. Foi um êxodo total. Agora tem as famílias q continuam [...]

$\mathrm{N}$ : A gente morava e trabalhava nas roças. Aí mudaram todo mundo para a cidade. Todo mundo agora quer saber de cidade. Porque, a represa foi boa pro pescador. Boa mais pra quem pesca e fica em beirada de água, isso foi muito bom.

O: Antes da represa, pra você ter ideia, Morada Nova tinha usina hidrelétrica, era na fazenda do meu pai que fornecia energia para a cidade. Aí veio a represa, tiraram o maquinário todo. Até então era "força e luz de MG", não havia Cemig. A energia aqui dentro da cidade era por motor, gerador. E com o passar de muitos anos que instalaram a energia elétrica que vinha de três marias.

O: O pessoal revoltou muito. Primeiro porque as melhores terras férteis e agricultáveis à margem do São Francisco (Extrema, Indaiá, Burrachudo etc.). Primeiro porque perderam as terras e as plantações. E segundo que não foram indenizadas por preço razoável. Lançaram um preço aí, se quisesse pegava, e se não quisesse ia ficar sem. E o pior de tudo, foi o êxodo. A maioria mudou para Unaí, Três Marias, Paracatu, João Pinheiro. Muitas casas ficaram fechadas aqui. E a população que era predominantemente rural, saiu de suas casas. E com a represa, seccionou totalmente o município. Da sede do município para a área rural, era necessário barco, canoa. Nos usávamos madeira daqui mesmo e fazíamos esses barcos, usávamos os de pesca. $\mathrm{Na}$ época, a Suvale fez uns barcos de 4 tambores com uma canoa no meio, expondo a vida de muita gente, para atravessar. Com o decorrer do tempo, foi melhorando, desenvolvendo aos poucos. A população foi lutando pelas melhorias, né? Ai depois substituíram as embarcações, melhoraram, eram mais adequadas, no porto novo - São José do Buriti. Mas com horário sempre determinado. E o meio de comunicação ainda era muito precário. Ai quando eu assumi a prefeitura, a nossa intenção era reestabelecer o acesso da área rural com a sede. Aí fizemos 3 aterros: Sucuriú de baixo, Sucuriú de cima e Extrema. Todas elas que dependiam de balsa. Na época fui denunciado e processado por ter feito os aterros. Na justiça federal, respondi processo 


\section{而

judicial por eu estar invadindo as posses da Cemig. Expliquei para o juiz que eu só queria tirar o povo da dependência de horário de balsa, dar autonomia. Ninguém queria invadir área da Cemig.

W: De forma que houve um deslocamento muito grande de pessoas. Biquinhas que era um Distrito de Morada, os distritos eram muito populosos, um total de 20 mil habitantes. Com isso, reduziu para 5 mil habitantes, para você ter ideia do êxodo que foi.

As estradas cobertas pelas águas, desvios que precisavam ser feitos. Um problema ecológico muito grande. Cobra em Morada entrava para a rua. Porque a água subiu até o fundo da cidade, e pegou alguma casa no fundo lá. E o problema de mudança, perdemos as coisas, chiqueiro, paiol. Não deu tempo de desmanchar nada na fazenda do meu pai. Um cruzeiro também. Pra você ver o que é que foi. De forma que foi um desastre para Morada, tá certo?

W: Naquela época a água foi o nosso desastre. Mas de forma que Morada Nova levantou em decorrência da água. Porque a água hoje, é o grande polo menor, vetor de desenvolvimento de Morada. Porque temos irrigação, mais de 6 mil hectares. A produção de tilápia em tanque rede é maior forma de emprego e desenvolvimento econômico nesse trabalho. No mínimo 500 pessoas vivendo diretamente da tilápia. É difícil fazer uma comparação. Apesar de que Morada era a cidade que mais produzia na região. Mais que Abaeté, produção agrícola e pecuária. Feijão, não tinha nem mercado, jogava fora de tanto que produzia. E vendia para Curvelo. E até hoje Morada Nova tem o maior potencial de todas as cidades que confrontam, só perde para Pompéu. Está à frente de Biquinhas, Paineiras, Abaeté, Tiros, São Gonçalo do Abaeté. Morada hoje ninguém segura. Nem uma péssima administração que tivemos aí, não segura. Depois, com a irrigação a pecuária voltou a desenvolver. Porque a terra é muito boa, e fizeram agricultura nas terras do cerrado, irrigada.

\subsection{DIREITOS E INDENIZAÇÃO}




\section{而

I: Teve até um que falou que concordou com o preço da indenização e está sem receber até hoje. Minha avó mesmo não recebeu.

I: [sobre indenização] Demorou anos e anos minha filha. Tinha advogado, todos eles. Papai tinha, todos advogados de fora. Recebeu muitos anos depois. O tanto de terra que todo mundo perdeu, mas o país não tinha mais dinheiro para pagar. Estava construindo Brasília. Foi aí que começou a inflação. As coisas ficaram caras, no mercado. A vida da gente ficou cara e até hoje foi só subindo o preço.

N: Aí a água veio, tirou todo mundo. Foi o que acabou com as roças, ninguém mais mexeu com roça. Foi aí que uns mudou, perderam casa, perdeu terreno, que a água tomou. Eles falam que indenizaram o povo que perderam as coisas, mas eu não tenho certeza não. Se indenizou ou não.

W: O povo era muito tranquilo e aceitava tudo com muita tranquilidade. Mas as melhores terras foram perdidas. Mas o pessoal que entrou na justiça ou não recebeu ou recebeu porcaria. Meu pai por exemplo, vendeu tudo que sobrou para pagar as dívidas. Ele ficou sem nada. Meu pai era vice-prefeito e foi trabalhar com a Codevasf na época. Eu não lembro bem porque morava em Belo Horizonte para trabalhar. Mas meu pai tinha um caminhão e ficava por conta de fazer a mudança do pessoal para Unaí. Eles atravessavam isso em barquinho vagabundo. Uma dificuldade grande. Três Marias, Unaí e João Pinheiro foram as cidades que mais receberam Moradenses.

\section{CONCLUSÕES}

Através das narrativas colhidas nas entrevistas, pode-se demarcar não apenas a seletividade da memória, traduzida nas diferentes narrativas e focos. Essa seletividade tem razões afetivas e sociológicas, simultaneamente. Alguns entrevistados selecionam aspectos do passado vivido ou imaginado que remetem a esperanças e expectativas específicas. Imaginam, por exemplo, que a perspectiva de modernização foi cortada pela represa. 


\section{而

A perspectiva de criação de gado, foi registrada com o foco recorrente da ideia de progresso e desenvolvimento, elementos que teriam se perdido com a chegada das águas; terra ou fazenda, mas também o gado eram vistos como foco da estruturação econômica; claro, a narrativa é localizada socialmente já que outros entrevistados enfatizaram as possibilidades abertas à piscicultura e à agricultura e outros lembraram que nem todas as fazendas teriam sido atingidas diretamente pelo projeto. Nesse registro, algumas das entrevistas inclusive minimizaram o evento da chegada das águas e do declínio da economia com dois tipos de argumentos. O primeiro de que as águas não atingiram a situação familiar ou pessoal de forma específica e em segundo lugar que foram criadas diferentes alternativas. As entrevistas adicionam zonas de significação aso processos históricos referenciados e à situação de Morada Nova de Minas. Os dados estatísticos dizem algo, mas as entrevistas acrescentam elementos fundamentais, quais sejam percepção e informações sobre processos vividos ou narrados.

Sob uma perspectiva ou registro teórico, ou melhor sob o conceito de desenvolvimento como liberdade, retirado de Amartya Sen, percebe-se que para sacrificar um modo de vida tradicional a fim de diminuir a pobreza ou saciar a fome, proteger o meio ambiente e aumentar a longevidade das pessoas, torna-se primordial a participação social em processos de decisão e implementação de ações públicas. A ausência de diálogo sobre o curso dos acontecimentos que envolvem decisões e ações fundamentais sobre a vida coletiva, se deslegitimam e se rompem expectativas de direitos. Conforme Sen, o desenvolvimento é um processo de expansão das liberdades reais que as pessoas desfrutam. Nelas estão incluídas as diferentes escolhas, superadas as situações de pobreza, autoritarismo e desigualdade. Então, é possível dizer que os dados estatísticos mostram forte migração, melhorias na situação de vida e abertura de possibilidades econômicas. As entrevistas confirmam essas informações, pelo menos em parte, mas revelam a gramática de atuação excludente, desorganizada e pouco participativa do poder público.

Para ilustrar como se movimentam as percepções, as representações e memórias dos moradores em relação à criação da hidrelétrica e em relação a ideia de 


\section{而 \\ ABDCONST}

desenvolvimento como liberdade agrupamos as entrevistas em temas. Certamente as preocupações dos Moradenses estão longe ou mesmo desconhecem o conceito de desenvolvimento como liberdade, mas o poder desse conceito se apresenta com toda a sua força quando se percebe que alguns de seus traços encontram-se na cultura comum de quem vivenciou e vivencia desafios relacionados à desproteção, insegurança alimentar, pobreza, desigualdades sociais, não reconhecimento de direitos e ausência de mecanismo de participação em acontecimentos que afetam a vida do dia a dia.

Os traços marcados pela história da cidade possuem peculiaridades similares a ocupações em diversos lugares do Brasil: a busca tardia por direitos, em sua maioria galgada na luta e união através de movimentos populares, de demanda de justiça através de ações coletivas, Ministério Público e coletivos inspirados em ideais de justiça e participação. O que se pretende, neste caso, é demonstrar que as exclusões, mas também a participação se constitui em processos coletivos, registrado nas memórias e nos corpos e nas instituições.

\section{REFERÊNCIAS}

ANA, Agência Nacional das Águas. Disponível em <http://www3.ana.gov.br/portal/ANA/> acessado em 26 de janeiro de 2019.

ANEEL, Agência Nacional de Energia Elétrica. Disponível em <http://www2.aneel.gov.br/scg/Consulta_Empreendimento.asp > acessado em $01 \mathrm{de}$ maio de 2019

BENJAMIN, Walter. O Narrador: considerações sobre a obra de Nikolai Leskov. In: Magia e técnica, arte e política: ensaios sobre literatura e história da cultura. São Paulo: Brasiliense, 1944, p.197-221.

BRASIL, Atlas do Desenvolvimento Humano do Brasil. Disponível em <http://atlasbrasil.org.br/2013/pt/perfil_m/206>, acessado em 03 de janeiro de 2019.

Constituição da República Federativa do Brasil. Brasília, DF, 1988. Disponível em: <http://www.planalto.gov.br/ccivil_03/constituicao/constituicaocompilado.htm> Acesso em 16 de abril de 2018. 


\section{.

. Presidência da República. Comissão do Vale do São Francisco. Represamento do São Francisco. Rio de Janeiro. 1953.

IBGE - Instituto Brasileiro de Geografia e Estatística. Censo Demográfico do Município de Morada Nova de Minas. Disponível em: https://cidades.ibge.gov.br/brasil/mg/morada-nova-de-minas acessado em 23 de abril de 2018.

Enciclopédia dos Municípios Brasileiros, XXVI Volume. 29 de maio de 1959.

Rio de Janeiro. Disponível em https://biblioteca.ibge.gov.br/visualizacao/livros/liv27295_26.pdf acessado em 05 de setembro de 2018.

Recenseamento do Brazil em $1872 . \quad$ IBGE: <https://biblioteca.ibge.gov.br/visualizacao/livros/liv27295_26.pdf> acessado em 03 de janeiro de 2019.

CEMIG. Companhia Energética de Minas Gerais S. A. Linha do Tempo. Disponível em $<\mathrm{http} / / / \mathrm{www} . c e m i g . c o m . b r / p t-$ br/a_cemig/Nossa_Historia/Paginas/linha_do_tempo.aspx > acessado em 23 de abril de 2018 .

CAMPELlO, Tereza; GENTILI, Pablo; RODRIGUES, Monica and HOEWELL, Gabriel Rizzo. Faces da desigualdade no Brasil: um olhar sobre os que ficam para trás. Saúde debate [online]. 2018, vol.42, n.spe3, pp.54-66. ISSN 0103-1104. http://dx.doi.org/10.1590/0103-11042018s305.

COMITE BRASILEIRO DE BARRAGENS. Disponível em $<$ http://www.cbdb.org.br/>acessado em 01 de maio de 2019.

CONSELHO NACIONAL DE POLÍTICA ENERGETICA. CNPE. Disponível em <http://www.mme.gov.br/web/guest/conselhos-e-comites/cnpe> Acessado em $01 \mathrm{de}$ maio de 2019.

DAYRELL, Ilda de Oliveira. Morada Nova de Minas e a Opinião Pública. Belo Horizonte. 1968.

GOMES, Erina Batista. Sombras, Brechas e gritos: Vozes silenciadas, consulta prévia e re-existência nas margens do rio Tapajós. Dissertação de Mestrado apresentada ao programa de Pós-graduação em Direitos Humanos e Cidadania da Universidade de Brasília. 2018. 
MAB: Movimento dos Atingidos por Barragens. Disponível em <http://www.mabnacional.org.br/content/1-final-da-decada-70-os-primeiros-passos> acessado em 08 de janeiro de 2019.

PAULA, Dilma Andrade de. A Usina Hidrelétrica de Três Marias, o Desenvolvimentismo Seletivo e o Papel de Intelectuais. Disponível em: <http://www.snh2017.anpuh.org/resources/anais/54/1488660290_ARQUIVO_anpuh2 017.pdf> Acesso em 21 de abril de 2018.

O debate parlamentar na criação da Comissão do Plano de Aproveitamento da Bacia do São Francisco (1946-1948): significados da atuação de Manoel Novaes. XXVIII Simpósio Nacional de História. 2015.

PUBLICA, Disponível em <https://apublica.org/2015/02/ninguém-os-ouviu/> acessado em 01 de maio de 2019.

RIBEIRO, Mônica Thaís de Souza. Documentário LÁ NA MORADA. Realizado em dezembro de 2016. Disponível em: https://www.youtube.com/watch?v=nSTN6Ci645I acesso em: agosto 2018.

SEN, Amartya Kumar. Desenvolvimento como liberdade: tradução Laura Teixeira Motta: Revisão técnica Ricardo Doniselli Mendes. São Paulo: Companhia das Letras, 2000.

SILVA, Frederico Augusto Barbosa da. Indicador de Desenvolvimento da economia da cultura. IPEA. Brasília. 2010.

FREIRE DE SOUZA, Érica B. C. Cartografias das subjetividades Brasileiras. IPEA. 2019.

Recebido em novembro de 2019.

Aprovado em janeiro de 2020. 